The Research Journal of the Costume Culture

[Original Article]
Received March 10, 2017

Revised March 24, 2017

Accepted March 28, 2017

${ }^{\dagger}$ Corresponding author

(chaemie61@hanmail.net)

ORCID

Eun Hie Kim

http://orcid.org/0000-0001-6373-0498

Hyunwoo Hwangbo

http://orcid.org/0000-0001-6649-2587

Jin-mie Chae

http://orcid.org/0000-0002-1408-6621

This research was financially

supported by Hansung

University.
pISSN 1226-0401

\section{The effects of meteorological factors on the sales volume of apparel products \\ - Focused on the Fall/Winter season -}

\author{
Eun Hie Kim, Hyunwoo Hwangbo ${ }^{*}$ and Jin Mie Chae ${ }^{* *+t}$ \\ BNE Trend Research, Korea \\ Graduate School of Information, Yonsei University, Korea ${ }^{*}$ \\ School of Global Fashion Business, Hansung University, Korea ${ }^{*}$

\section{기상요인이 의류제품 판매량에 미치는 영향 \\ - $\mathrm{F} / \mathrm{W}$ 판매데이터(9월 익년 2월)를 근거로 -}

\author{
김은희 · 황보현우 ${ }^{*}$ 채진미 ${ }^{\star *+}$ \\ BNE Trend Research, 연세대학교 정보대학원", \\ 한성대학교 글로벌 패션산업학부
}

\begin{abstract}
The purpose of this study was to investigate meteorological factors' effects on clothing sales based on empirical data from a leading apparel company. The daily sales data were aggregated from "A" company's store records for the Fall/Winter season from 2012 to 2015 . Daily weather data corresponding to sales volume data were collected from the Korea Meteorological Administration. The weekend effect and meteorological factors including temperature, wind, humidity, rainfall, fine dust, sea level pressure, and sunshine hours were selected as independent variables to calculate their effects on A company's apparel sales volume. The analysis used a SAS program including correlation analysis, $t$-test, and multiple-regression analysis. The study results were: First, the weekend effect was the most influential factor affecting sales volume, followed by fine dust and temperature. Second, there were significant differences in the independent variables'effects on sales volume according to the garments' classification. Third, temperature significantly affected outer garments'sales volume, while top garments' sales volume was not influenced significantly. Fourth, humidity, sea level pressure and sunshine affected sales volume partly according to the garments' item. This study can provide proof of significant relationships between meteorological factors and the sales volume of garments, which will serve well to establish better inventory strategies.
\end{abstract}

Keywords: meteorological factor(기상요인), sales volume(판매량), weekend effect(주 말효과), temperature(평균기온), fine dust(미세먼지)

\section{Introduction}

주로 패션시장에서의 매출 성과에 영향을 미치는 요인으로 전반적인 경제 상황, 
기업의 판매 전략, 패션 트렌드나 소비자 심리 등을 생각할 수 있는데, 최근에는 날씨가 매출에 영향을 미치는 중요한 변수로 대두되고 있다. 특히 시장규모 가 큰 아웃도어 브랜드들에게 날씨는 매출에 영향을 줄 수 있는 주요한 요인이 되고 있다. 현재 성숙시장 으로 시장이 포화된 상태인 아웃도어 브랜드들은 최 근 몇 년간 매출 둔화에 고전하고 있는데, 실제로 2016년의 경우 11 월의 포근한 날씨는 아웃도어 브랜 드들의 매출 급감을 불러일으키는 원인이 되었다. 평 년에 비해 이상 고온을 보인 초겨울의 날씨는 매출을 감소시키는 원인으로 파악되었고, 매출의 역신장을 초래한 요인으로 평가되었다.

연구자들은 날씨가 상품판매와 연관이 있다는 근 거로 날씨에 따라 소비심리와 구매행동이 영향을 받 기 때문이라고 설명하고 있다. 따라서 날씨가 소비자 의 구매심리에 미치는 영향을 밝히고, 이를 마케팅에 활용함으로써 기업은 판매를 증가시키고, 이윤을 증 가시키는 효과를 낼 수 있다고 보고하고 있다(Agnew \& Palutikof, 1999; Niemira, 2005). 이처럼 날씨 정보 를 전략적으로 이용하여 경영에 활용하는 기법을 날 씨 마케팅이라고 한다(Lee, Ahn, \& Chung, 2011).

날씨는 모든 산업분야에 직, 간접적으로 영향을 미 치고 있는데, 날씨가 직접적인 영향을 주는 농업, 에 너지 산업 이외에 의류 산업은 유통, 레저, 식음료 산 업과 함께 날씨에 민감하게 반응하는 산업군으로 분 류된다. 의류상품은 계절상품이며, 기상 조건에 따라 착용하는 품목과 스타일이 달라지기 때문이다. 즉, 소 비자가 기상요인에 의한 필요에서 목적 구매를 하는 상품이면서 동시에 날씨에 따라 변화되는 소비 심리 로 인해 충동구매를 하기도 하는 상품이다. 이러한 점에서 기상 정보는 의류 산업에서 상품 개발 시 고 려해야 하는 필수 사항이면서 소비심리를 자극해 판 매를 촉진시키는 면에서도 유용하게 활용될 수 있다.

실제로 기업들은 상품 기획의 첫 단계인 스타일 구 성(assortment planning)에서 날씨 정보를 활용해 품 목을 발굴하거나 스타일을 개발하는데 활용하고 있 다. 또, 날씨의 장기예보 정보를 활용해 수요 예측을 하고, 이에 따라 적정량의 생산을 진행하고 있다. 상 품 출시 이후에는 날씨 정보를 이용해 소비자의 구매 욕구를 자극할 수 있도록 매장의 디스플레이를 구성 하여 소비를 유도하고 있다. 광고캠페인에 날씨에 적
합한 착장법과 기능성 상품을 제안하는 방식으로 홍 보 전략에 활용하고 있다. 예를 들어 유니클로는 가 을 간절기가 길어진다는 예보를 기반으로 간절기를 겨냥한 폴라플리스 재킷을 구성하여 15 일 만에 1,500 만장을 판매하였고(Ji \& Kim, 2010), 헌터는 2013년 장마가 길어진다는 기상예보에 맞춰 공급량을 증대 해 매출이 전년 대비 $50 \%$ 이상 성장했으며(Park, 2013), (주)블랙야크는 상품 생산량 결정시 날씨 요인을 포함 한 수요예측을 시행해 적정량을 생산하였고, 날씨를 활용해 매장의 디스플레이를 변경하는 등 홍보 전략 의 성공으로 2013 년 매출이 $29 \%$ 증가하는 성과를 거 두었다(Korea Meterological Administration, 2014).

이처럼 의류산업에서 날씨의 중요성은 커지고 있 지만 아직까지 날씨와 매출의 연관성을 분석하여 날 씨가 판매량에 미치는 영향을 실증적으로 검증한 선 행연구는 많지 않다. 따라서 본 연구는 국내 패션 전 문기업 $\mathrm{A}$ 사의 신사복, 캐주얼, 스포츠 브랜드의 4년 간 실제 매출 자료를 분석하여 날씨가 기업의 매출성 과에 어떠한 영향을 주는지 분석하고자 하였다. A사 의 경우 최적 생산량과 타이트한 재고관리 전략을 경 쟁요소로 삼아 의사결정을 하고 있었으므로 정확한 생산량의 예측을 위해 매출의 영향요인을 면밀히 밝 히는 분석이 필요했다. 특히 최근에 이상 기온으로 변동성이 확대된 변수인 기상요소가 제품 판매량에 미치는 영향은 많은 의류기업들의 관심이 되고 있으 므로 전문적인 데이터 마이닝 기법을 이용하여 기상 요인의 영향력을 분석하고자 하였다. 이러한 시도는 향후 상품 기획 시 날씨의 영향력을 제외한 매출을 산출해 활용하거나, 날씨예보 정보를 활용해 수요 예 측을 하는 등, 생산량을 의사 결정하기 위한 지침 또 는 방향을 제시하는데 활용할 수 있을 것으로 판단된 다. 이를 통해 적정량의 생산과 최적의 재고관리를 위한 경영 기법을 개발할 수 있다면 이미 성숙시장이 된 의류시장에서 경쟁우위를 달성할 수 있는 근거가 될 수 있을 것이다.

\section{Background}

1. The relationship between meteorological factors and product sales

기상요인과 기업의 매출이 밀접하게 관련되어 있 
다는 전제하에 기업 내부나 연구소에서는 보고서가 발표되고 있다. LG경제연구소에서는 기상 요소 가운 데 임계 온도에 따른 상품 판매량의 관계를 설명하고 있는데, 예를 들면 콜라는 $25^{\circ} \mathrm{C}$ 이상에서 매출이 급 격히 증가되며, $1^{\circ} \mathrm{C}$ 증가에 따라 매출이 $15 \%$ 씩 증가 하고, 아이스크림은 $25 \sim 30^{\circ} \mathrm{C}$ 에서 매출이 급증하며, 맥주의 경우 $1{ }^{\circ} \mathrm{C}$ 증가에 따라 매출이 $3 \%$ 씩 증가한다 고 보고하였다. 우유나 요구르트는 $20 \sim 30^{\circ} \mathrm{C}$ 로 기온이 상승할 때 매출은 약 $8 \%$ 씩 감소한다고 하였고, 의류 제품인 경우 대표적으로 정장 수트는 낮 최고기온이 $27^{\circ} \mathrm{C}$ 이상일 때는 매출이 감소하며, 20 27 ${ }^{\circ} \mathrm{C}$ 일 때 온 도에 따라 매출이 증가한다고 하였다(Lee, 1997).

일본에서도 이와 비슷한 조사로 의류제품이 본격 적으로 팔리기 시작하는 임계 온도를 조사하였는데, 반소매 셔츠는 $19^{\circ} \mathrm{C}$ 에서 판매가 현저히 증가하였고, 방한의류는 $10^{\circ} \mathrm{C}$, 장갑은 $13^{\circ} \mathrm{C}$ 에서 본격적으로 팔리 기 시작한다고 하였다(Lee, 1997). 근래에는 날씨 마 케팅의 일환으로 우리나라에서도 기온이 제품 판매 량에 미치는 영향을 조사한 보고서가 나오고 있다. 날씨 정보회사인 $\mathrm{K}$ 웨더에 의하면 여름 매출은 6 월의 온도가 높을 때, 겨울 매출은 11 월의 온도가 낮을 때 시즌 매출이 증가하는 경향을 보인다고 하였다(Bahn, 2011). 유통채널의 매출도 기상 요인에 따라 변화하 는데, 백화점의 매출은 맑은 날의 매출이 비오는 날 에 비해 $10 \%$ 이상 증가한다고 하며, 이에 반해 홈쇼 핑의 매출은 비오는 날의 주문이 맑은 날의 주문에 비해 $25 \%$ 증가한다는 결과가 보고되었다(Byun, 2000). 이와 같이 계절이 제품의 매출에 영향을 미치고, 계절성 중에서 특히 기온의 변화에 따라 상품의 판매 량이 급격히 증가하는 온도가 있는 것으로 확인되면 서 기온과 제품의 매출에 어떠한 관계가 있는지 밝히 려는 연구가 증가하고 있다. 또한 날씨 정보를 기업 경영에 접목시켜 의사결정 단계에 활용하기도 한다 (Kim \& Kim, 2006). 예를 들어 유통 및 제조업체, 의 류업체들은 날씨에 맞는 상품 수요를 미리 예측하여 적정 생산량을 생산함으로써 생산비 감축이나 효율 적인 재고관리를 실행하고 있으며, 레저 및 관광 업체 들은 날씨에 따른 이벤트 기획과 고객 수 예측 등 날 씨 정보를 마케팅 활동에 이용하고 있다(Ahn, 2008). 수요를 산출할 때 학문적인 관점에서도 트렌드(trend), 주기(cycle), 계절성(seasonality)과 불규칙성(irre- gularity)의 네 가지 요소로 설명이 가능하다고 받아들 여지고 있으므로(Lee, 1997), 계절성 중에서 많은 부 분을 설명할 수 있는 기온을 비롯한 기상요인에 초점 을 두고 판매량과의 연관성을 살펴보는 것은 의의가 있다고 하겠다.

\section{Effects of meteorological factors on sales of} apparel products

앞서 다양한 제품군에 따라 계절성과 기온이 영향 을 미치는 것을 살펴본 것에 이어 의류제품에 특정하 여 기상요인과의 관계를 밝힌 선행 연구를 살펴보고 자 한다. 의류제품이 계절상품이므로 기상요인이 매 출에 영향을 미치는 사실은 널리 알려져 있지만, 기 상요인과 매출의 관계를 실증적으로 검증한 학문적 인 연구는 상대적으로 많지 않은 실정이다. 주제별로 는 날씨 요인이 소비심리와 구매행동에 미치는 영향 을 고찰한 연구, 기상 요인이 매출에 미치는 영향력 을 분석한 연구, 평년기온과의 기온편차가 매출에 미 치는 상관지수를 산출한 연구들이 있으며, 대부분 구 체적인 가설검정보다는 실제 판매데이터를 기반으로 기상요인이 매출에 미치는 영향관계를 회귀분석을 통해 현상학적으로 탐색한 연구가 이루어졌다.

Yun(1999)은 기상요인을 고려한 영업 판매량계획 을 수립하는 기업정보시스템 모델 설계연구에서 날 씨가 맑은 날이 흐리거나 눈, 비오는 날에 비해 의류 제품의 매출이 높다는 결과를 보고하였으며, Park (2004)은 기온과 강수가 대형 할인점의 상품판매에 서로 다른 영향을 미친다고 하였다. Hong, Lee, and $\mathrm{Na}$ (2012)는 대형할인점의 매출자료를 분석한 결과, 여름용품인 수영복과 우산의 경우 기온상승과 함께 매출액이 증가하고, 강우량이 매출에 유효한 변수로 나타났으며, 겨울용품인 머플러, 장갑, 동내의의 경우 는 기온이 하락할 때 매출이 증가하며, 적설량과 유 의한 관계가 있음을 확인하였다.

Jang and Lee(2002)는 백화점의 3년 매출자료를 대상으로 기상요인이 매출액에 미치는 영향을 다중 회귀분석을 통해 분석한 결과, 기상요인 가운데 기온 이 가장 큰 영향을 미쳤으며, 강수량, 일조와 풍속의 순으로 나타났다고 하였다. 남성복 중에서 정장류의 경우, 가을에는 기온이 낮을수록 매출이 높아지며, 겨 울에는 영향이 없는 것으로 나타났고, 스포츠 의류는 
수영복, 스키복의 영향으로 여름에는 기온이 높을수 록, 겨울에는 기온이 낮을수록 매출이 높아졌다고 하 였다. Jang and $\operatorname{Lim}(2003)$ 은 백화점에 입점한 남성 복, 여성복 브랜드의 3 년 매출을 대상으로 기상요인 과 백화점에서 실시하는 정기세일이 복종별 매출에 주는 영향을 밝혔는데, 정기세일이 기상요인보다 높 은 영향력을 나타낸다고 하였다. 복종별 분석에서 남 성복은 여성복에 비해 기상요인의 영향을 덜 받는 것 으로 나타났고, 가을, 겨울에는 기온의 영향이 없었으 며 겨울에는 바람이 많을수록 매출이 높아진다고 하 였다.

Lee et al.(2011)은 의류 전문브랜드의 1년 매출액 에 대한 기온과 습도의 관계를 다중회귀분석으로 밝 혔는데, 남성복 브랜드의 경우 가을, 겨울에는 온도가 매출에 영향을 미치지 않았고, 습도가 높을수록 매출 에 부정적인 영향을 주었다고 하였다. 캐주얼웨어 브 랜드는 가을, 겨울시즌 모두 온도가 낮을수록 매출이 높아졌고, 가을에는 습도가 부정적인 영향을 주었다 고 밝혔다. 이상의 연구들은 점포의 매출데이터를 기 반으로 기상요인이 주는 영향력을 밝히고자 하였으 며, 백화점의 매출자료를 기반으로 분석할 때 백화점 의 정기세일 효과를 고려한 점 외에는 다른 영향변수 들에 대한 통제는 엄격하게 이루어지고 있지 않음을 알 수 있다.

기상요소와 소비심리와의 관계를 밝힌 연구를 살 펴보면, Rowley(1999), Stoltman, Morgan, and An$\operatorname{glin}(1999)$ 은 각각 비와 흐린 날씨가 구매행동에 부정 적인 영향을 미쳐, 소비자들의 쇼핑가능성이 낮아진 다고 하였다. 기상요소와 쇼핑센터의 매출 및 쇼핑객 트래픽의 관계를 검증한 Parsons(2001)의 연구에 의 하면 기온과 강수량에 따라 뉴질랜드 쇼핑센터의 일 별 쇼핑객수는 변화하였으며, 비가 오거나 최고기온 으로 올라가면 쇼핑객이 감소하는 결과가 나타났다. 상대습도, 일조시간은 쇼핑객의 숫자에 영향을 미치 지 않는다고 하였다. 회귀분석을 통해 날씨 요인 이 외에도 쇼핑센터의 매출에 영향을 주는 요인으로 휴 일효과, 주말효과가 있음을 밝혀냈다.

Bahng and Kincade(2012)는 기상요소와 판매량의 관계를 밝히는 연구에서 $\mathrm{SKU}$ (store keeping unit) 단 위로 판매 패턴을 기술적으로 분석하고, 제품 속성과 의 연관성을 설명하였다. 연구결과에 의하면 기온 변
화는 각각의 의류 제품의 판매패턴에 영향을 미치는 데, 가을, 겨울 시즌에는 온도가 급격하게 감소하면 주별 판매수량이 급속히 증가하고, 판매 패턴에서도 증가하는 추세가 나타났다. 반면, 일별, 주별로 기온 이 일정한 편차 내에서 변동하는 경우에는 판매패턴 에서도 급격한 파장이 발생하지 않으며 판매량에도 큰 변화가 나타나지 않는다고 하였다. 제품 간 판매 패턴은 상품 속성에 따라 다르게 나타났는데, 계절감 을 반영하는 소재와 패브릭의 중량, 컬러의 밝고 어 두움이 영향을 미쳐, 한 예로 소재가 두껍고 긴 기장 의 재킷이 짧은 기장의 재킷에 비해 겨울동안 긴 형 태의 판매패턴을 보였다.

Arunraj and Ahrens(2016)는 독일의 3개 점포의 매 출을 대상으로 식품과 의류제품의 날씨 요인의 차이 점을 분석한 결과, 식품에 비해 의류제품이 날씨 요 인의 영향을 더 많이 받는 상품임을 밝혔다. 가을, 겨 울에는 온도가 낮을수록 의류 제품의 매출이 높고, 봄에는 온도가 높을수록 매출이 높은 것으로 나타났 으며, 눈은 의류제품의 쇼핑을 미루는 효과가 있어서 눈이 온 이후에 4 6일 정도 쇼핑의 지연효과가 나타 난다고 하였다. 비는 당일 쇼핑객의 숫자를 감소시키 는 효과가 있으며, 매출에는 영향을 미치지 않는다고 하였다.

의복 매출과 온도의 관계를 검증함에 있어서 Bertrand, Brusset, and Fortin(2015)은 프랑스 패션산업 전체의 월간 매출 IFM(Institut Français de la Mode) 통계와 기온과의 상관성을 분석하였는데, 봄, 가을이 기온과 매출의 연관관계가 가장 높게 나타난 계절이 며, 봄에는 날씨가 따뜻할수록, 가을에는 날씨가 추울 수록 매출이 증가한다고 밝혔다. 상관성은 2000 2014년 판매 데이터를 기초로 기온 대비 월별 매출액 에 미치는 영향력이 $-7 \% \sim 7.3 \%$ 정도이며, 편차는 1.9 $\%$ 라고 보고했다. 이 결과는 Marteau, Carle, Fourneaux, Holz, and Moreno(2004)의 연구에서도 비슷하게 도출되었으며, 온도와 의복매출의 상관계수가 높은 달은 $3,4,5$ 월과 $9,10,11$ 월이라고 하였다.

이와 같은 선행연구들에서 기상요인 중 온도와 매 출의 영향관계가 가장 많이 보고되었고, 이외에 강수 량, 습도, 풍속, 일조시간의 효과가 일부 밝혀졌다. 본 연구에서는 기상요인이 $\mathrm{A}$ 기업의 브랜드 판매량에 미 치는 효과를 데이터분석을 통해 실증적으로 분석하 
기 위해 구체적인 기상요인들을 선정하였고, 신사복, 캐주얼, 스포츠 브랜드별로 어떤 차이를 가지고 영향 력을 미치는지 분석하고자 하였다.

\section{Methods}

\section{Research question}

$\mathrm{A}$ 기업이 보유하고 있는 대표적인 신사복 브랜드, 캐주얼 브랜드, 스포츠 브랜드의 의류제품 판매량 데 이터를 기반으로 의류제품 판매량에 영향을 주는 다 양한 기상요인을 실증적으로 분석하고자 하였다.

연구문제 1: 의류제품 판매량에 영향을 주는 다양 한 기상요인을 밝힌다.

연구문제 2: 복종별/품종별로 주말효과와 기상요인 이 의류제품 판매량에 미치는 영향을 밝힌다.

\section{Data collection}

본 연구를 위하여 $\mathrm{A}$ 의류기업이 보유하고 있는 브 랜드의 의류제품에 대한 일별 매출자료와 기상청에 서 제공한 기상요인들에 대한 자료가 사용되었다.

\section{1) Sales data of a apparel company}

국내 의류기업인 $\mathrm{A}$ 기업이 보유하고 있는 신사복 브랜드, 캐주얼 브랜드 스포츠 브랜드들의 일별 판매 량 자료를 수집하였다. 선행연구들이 제품 매출액에 대한 기상효과를 분석했지만(Hong et al., 2012; Jang \& Lee, 2002; Jang \& Lim, 2003; Lee et al., 2011), 의류제품은 품종별로 가격편차가 많음을 고려하여 본 연구에서는 판매량 자료를 선정하였다. 또한 의류 제품의 판매는 계절적 영향을 많이 받는 것으로 판단 되므로 계절에 따른 영향을 통제하기 위하여 2012 년 2015년의 4년 동안의 $\mathrm{F} / \mathrm{W}$ 시즌(9월 익년 2월)제 품만을 대상으로 하였으며, 전국에 분포되어 있는 관 련 브랜드들의 매장의 POS시스템에 기록된 총 725 일 의 브랜드별 일일 판매데이터를 분석에 사용하였다. 품종은 각 브랜드에서 outer(코트, 재킷, 점퍼), top(셔 츠/블라우스, 티셔츠), pants를 포함시켰으며, 해당시 즌 정상제품 중에서 100 개 이상 판매된 상품을 추출 하였다.

\section{2) Meteorological data}

기상청이 보유하고 있는 데이터 중 2012년 2015 년의 9월 익년 2월 동안의 일별 판매량 데이터를 사 용한 총 725 일에 대한 전국 기상요인 데이터의 평균 값을 사용하였다. 평균기온, 최고기온, 최저기온, 풍 속, 습도, 강수량, 전운량, 열지수, 1 시간 최다일사, 적 설량 등 29 개의 기상요인 중 활용성을 검토하여 1 단 계로 14 개의 기상변수를 선정하였다. 2 단계로 각 변 수간의 상관관계가 높은 변수들을 파악하기 위하여 피어슨의 상관관계분석을 시행하여 상관계수 0.7 이 상인 변수를 제거하고, 되도록 다양한 기상요인들의 영향의 정도를 파악하기 위해 최종적으로 7개의 기상 요인을 선정하였다.

(1) 평균기온(temperature: $\left.{ }^{\circ} \mathrm{C}\right)$ : 해당일의 기온의 평 균값을 의미한다.

(2) 풍속(wind: $\mathrm{m} / \mathrm{s}$ ): 단위시간 당 이동하는 공기의 속도를 의미한다.

(3) 습도(humidity: \%): 공기 중에 포함된 수증기의 비율로 공기의 건습정도를 의미한다.

(4) 강수량(rainfall: $\mathrm{mm}$ ): 지표면에 내린 강수의 총 량으로 비, 눈, 우박 등을 포함한 양을 의미한 다.

(5) 미세먼지농도(fine dust: $\mu \mathrm{g} / \mathrm{m}^{3}$ ): 공기 중에 포함 된 미세먼지 농도를 의미한다.

(6) 해면기압(sea level pressure: $\mathrm{hPa}$ ): 관측소 기압 에 해면경정을 하여 얻은 평균 해수면 높이에서 의 기압을 의미한다.

(7) 일조량(sunshine: hr): 하룻 동안 태양광선이 지 표면에 비친 시간을 의미한다.

최종적으로 선정한 기상요인들 간의 상관관계 분 석결과는 〈Table 1)과 같다. 대부분 선정한 기상요인 들 간에 낮은 상관성을 보였으며, 평균기온과 해면기 압은 - .649, 습도와 해면기압은 -.494, 습도와 일조량 은 -.583으로 상대적으로 높은 부적 상관을 나타냈다.

\section{Data analysis}

수집한 일별 판매량 데이터를 볼 때, 토, 일요일의 판매량이 주중(월 금) 판매량보다 높음을 파악하고, 주중/주말의 판매량에 있어서 통계적으로 유의한 차 
$<$ Table 1> Correlation analysis of meteorological factors

\begin{tabular}{c|c|c|c|c|c|c|c}
\hline & Temperature & Wind & Humidity & Rainfall & Fine dust & Sea level & Sunshine \\
\hline Temperature & 1.000 & & & & & & \\
\hline Wind & $-.217^{* * *}$ & 1.000 & & & & & \\
\hline Humidity & $.361^{* * *}$ & -.007 & 1.000 & & & & \\
\hline Rainfall & $.165^{* * *}$ & $.227^{* * *}$ & $.419^{* * *}$ & 1.000 & & & \\
\hline Fine dust & $-.169^{* * *}$ & -.029 & .013 & $-.108^{* *}$ & 1.000 & & \\
\hline Sea level & $-.649^{* * *}$ & $-.221^{* * *}$ & $-.494^{* * *}$ & $-.325^{* * *}$ & $.108^{* *}$ & 1.000 & \\
\hline Sunshine & .021 & -.052 & $-.583^{* * *}$ & $-.368^{* * *}$ & -.027 & $.159^{* * *}$ & 1.000 \\
\hline${ }^{*} p<.05,^{* *} p<.01,{ }^{* * *} p<.001$. & & & &
\end{tabular}

<Table 2> Differences in sales volume of weekdays/weekend

(Unit: piece)

\begin{tabular}{c|c|c|c|c|c|c|c|c|c|c}
\hline \multirow{2}{*}{ Year } & \multicolumn{2}{|c|}{2012} & \multicolumn{2}{c|}{2013} & \multicolumn{2}{c|}{2014} & \multicolumn{2}{c|}{2015} & \multicolumn{3}{c}{ Total } \\
\cline { 2 - 10 } & Weekdays & Weekend & Weekdays & Weekend & Weekdays & Weekend & Weekdays & Weekend & Weekdays & Weekend \\
\hline $\begin{array}{c}\text { Mean } \\
\text { (SD) }\end{array}$ & $2,119.1$ & $3,562.5$ & $2,020.9$ & $3,590.1$ & $2,921.0$ & $5,002.3$ & $2,839.5$ & $3,940.8$ & 2301.3 & $3,750.4$ \\
$(2,309.7)$ & $(3,892.0)$ & $(2,408.5)$ & $(4,301.4)$ & $(1,650.1)$ & $(2,900.1)$ & $(1,550.9)$ & $(1,894.3)$ & $(2,142.8)$ & $(3,599.5)$ \\
\hline$t$-value & \multicolumn{2}{|c|}{$3.842^{* * *}$} & \multicolumn{2}{|c|}{$4.111^{* * *}$} & \multicolumn{2}{c|}{$6.105^{* * *}$} & \multicolumn{2}{c|}{$4.130^{* * *}$} & \multicolumn{2}{c}{$7.870^{* * *}$} \\
\hline$* * *$
\end{tabular}

*** $p<.001$.

이가 있는지를 보기 위하여 $t$-test를 시행하였다(Table 2). 그 결과, 주중/주말의 판매량은 유의한 차이가 있 음이 분석되었고, Parsons(2001)는 뉴질랜드 쇼핑센 터의 매출에 날씨 요인 이외에 휴일효과, 주말효과가 영향을 미친다고 하였듯이 주말효과도 판매량에 영 향을 미칠 것으로 판단하였다. 그러므로 독립변수로 는 기상요인인 평균기온, 풍속, 습도, 강수량, 미세먼 지농도, 해면기압, 일조량을 선정하였고, 주말효과는 더미변수로 처리하여 투입하였으며, 종속변수로는 상 품의 일별 판매량을 사용하였다. 통계분석은 $\mathrm{SAS}^{\circledR}$ 9.4와 $\mathrm{SAS}^{\circledR}$ Enterprise Miner 14.1을 사용하였다.

\section{N. Results}

1. Effects of meteorological factors on sales volume of apparel products

$\mathrm{A}$ 기업이 보유한 브랜드에 있어서 기상요인이 의류 제품 판매량에 미치는 영향을 밝히기 위해 다중회귀 분석을 시행하였고, 분석결과는〈Table 3 〉과 같다. 다
중공선성을 검토한 결과, Tolerance는 .10 이상이고, VIF지수는 10 이하로 다중공선성의 문제는 없었다. 전체 의류 판매량에 가장 큰 영향을 미치는 요인은 주말 효과로 나타나 Parsons(2001)의 연구결과를 지 지하였다. 기상요인 중에서는 평균기온과 미세먼지농 도가 영향을 미침이 밝혀졌다. 기온요인은 선행연구 에서도 매출에 영향을 주는 요인으로 밝혀진 바 있으 며(Arunraj \& Ahrens, 2016; Bertrand et al., 2015; Jang \& Lee, 2002; Jang \& Lim, 2003), 평균기온이 낮을수록 판매량이 증가하는 것으로 입증되었다. $\mathrm{F} / \mathrm{W}$ 시즌의 판매량을 분석한 결과이므로 소비자들은 기온이 내려갈수록 월동준비용 의류제품을 구매하기 위해 점포를 많이 방문할 것으로 추론된다. 특히 미 세먼지농도는 기상요인 중에서 판매량에 가장 많은 영향을 미친 기상 요인으로 분석되었는데, 본 연구에 서 실증적인 판매데이터를 근거로 데이터 마이닝 기 법을 활용해 기상요인과 판매량과의 관계를 밝혔다 는데 의의가 있다. 소비자들은 미세먼지농도가 높을 경우 외출을 자제하게 되고, 쇼핑을 위한 점포방문도 
$<$ Table 3> Effects of meteorological factors on sales volume of apparel products

\begin{tabular}{|c|c|c|c|c|c|c|c|}
\hline \multirow{2}{*}{$\begin{array}{l}\text { Dependent } \\
\text { variable }\end{array}$} & \multirow{2}{*}{ Independent variable } & \multirow{2}{*}{$\begin{array}{c}\text { Parameter } \\
\text { estimate }\end{array}$} & \multirow{2}{*}{$t$} & \multirow{2}{*}{$F$} & \multirow{2}{*}{$R^{2}$} & \multicolumn{2}{|c|}{ Multicollinearity } \\
\hline & & & & & & Tolerance & VIF \\
\hline \multirow{8}{*}{$\begin{array}{c}\text { Sales } \\
\text { volume }\end{array}$} & Weekend effect & $1,385.860$ & $7.504^{* * *}$ & \multirow{8}{*}{$10.480^{* * *}$} & \multirow{8}{*}{.077} & .981 & 1.020 \\
\hline & Temperature $\left({ }^{\circ} \mathrm{C}\right)$ & -28.768 & $-2.127^{*}$ & & & .409 & 2.443 \\
\hline & $\operatorname{Wind}(\mathrm{m} / \mathrm{s})$ & 38.006 & .332 & & & .682 & 1.465 \\
\hline & Humidity(\%) & 17.874 & 1.959 & & & .448 & 2.234 \\
\hline & Rainfall(mm) & -.542 & -.034 & & & .728 & 1.373 \\
\hline & Fine $\operatorname{dust}\left(\mu \mathrm{g} / \mathrm{m}^{3}\right)$ & -5.695 & $-2.841^{* *}$ & & & .941 & 1.062 \\
\hline & Sea level(hPa) & 25.293 & 1.158 & & & .376 & 2.658 \\
\hline & Sunshine(hr) & 34.313 & 1.119 & & & .576 & 1.736 \\
\hline
\end{tabular}

줄어듬을 알 수 있으므로, 의류업체는 기상요인 중에 서 미세먼지농도에 관심을 갖고 관측해야 함을 시사 한다. 반면에, 풍속과 강수량이 계절별로 남성복과 여 성복의 매출에 부분적으로 유의한 영향을 미친다고 한 Jang and $\operatorname{Lim}(2003)$ 의 연구결과는 달리 유의한 영 향이 없는 것으로 분석되었다.

\section{Effects of meteorological factors on sales} volume of apparel products according to apparel classification/item

$\mathrm{A}$ 기업이 보유하고 있는 브랜드들 중에서 복종/품 종별로 기상요인이 의류제품 판매량에 미치는 영향 을 분석하기 위하여 다중회귀분석을 시행하였다. 복 종은 대표적인 신사복 브랜드(men's formal wear), 캐 주얼 브랜드(casual wear), 스포츠 브랜드(sports wear) 를 선정하였고, 각 복종 내에서 품종을 코트, 재킷, 점 퍼를 outer, 셔츠/블라우스와 티셔츠를 top, 바지를 pants로 분류하여 분석하였다.

\section{1) Men's formal wear}

신사복 브랜드에 대해 기상요인이 제품 판매량에 미치는 영향에 대한 분석 결과는 〈Table 4〉와 같다. outer의 경우, 주말효과의 영향이 가장 컸으며, 평균 기온이 낮을수록, 습도가 높을수록 판매량이 증가하 는 것으로 나타났다. Top의 경우, 주말효과의 영향이
가장 크고, 습도가 높을수록, 해면기압이 높을수록 판 매량이 증가하였으며, pants의 경우는 역시 주말효과 의 영향이 가장 크고, 평균기온이 낮을수록, 해면기압 이 높을수록 판매량이 증가하는 것으로 나타났다.

평균기온과 습도의 영향은 Lee et al.(2011)의 연구 에서도 그 영향이 입증된 바 있으며, outer와 pants는 기상요인 중 평균기온의 영향을 많이 받아 기온이 하 강함에 따라 판매량이 증가하는 것으로 분석되었고, 특히 가을/겨울에는 기온이 낮을수록 의류제품의 매 출은 높아진다고 한 Arunraj and Ahrens(2016), Lee et al.(2011)의 결과를 지지하였다. 해면기압이 높음은 고기압으로 날씨가 맑음을 의미한다. 신사복 브랜드 에서만 해면기압이 판매량에 유의한 영향을 주는 것 으로 나타났는데, 캐주얼이나 스포츠 브랜드를 구매 하는 소비자층이 맑은 날 야외활동이나 스포츠를 즐 기는 반면, 신사복 브랜드를 찾는 소비자층은 쇼핑을 즐기는 것이 아닌가 추론해 본다.

주말효과는 품종에 관계없이 판매량에 가장 큰 영 향을 주는 요인임이 밝혀졌고, 세 품종 중 outer에 있 어서 주말효과와 기상요인이 판매량에 미치는 영향 이 가장 큰 것으로 분석되었고, 다음에 pants, top 순 이었다. 특히 outer는 모든 브랜드에서 평균기온의 영 향을 가장 많이 받는 품종으로 나타나, 다른 품종에 비해 수요예측 측면이나 매장 출고시기를 결정할 때 온도 정보를 활용하는 것이 필요함을 시사한다. 예를 
$<$ Table 4> Effects of meteorological factors on sales volume of man's formal wear

\begin{tabular}{|c|c|c|c|c|c|c|c|c|}
\hline \multirow{2}{*}{\multicolumn{2}{|c|}{ Dependent variable }} & \multirow{3}{*}{$\begin{array}{c}\text { Independent variable } \\
\text { Weekend effect }\end{array}$} & \multirow{3}{*}{$\begin{array}{c}\begin{array}{c}\text { Parameter } \\
\text { estimate }\end{array} \\
127.702\end{array}$} & \multirow{2}{*}{$t$} & \multirow{2}{*}{$F$} & \multirow{2}{*}{$R^{2}$} & \multicolumn{2}{|c|}{ Multicollinearity } \\
\hline & & & & & & & Tolerance & VIF \\
\hline \multirow{24}{*}{$\begin{array}{c}\text { Sales } \\
\text { volume } \\
\text { of man's } \\
\text { formal } \\
\text { wear }\end{array}$} & \multirow{8}{*}{ Outer } & & & $22.740^{* * *}$ & \multirow{8}{*}{$95.882^{* * *}$} & \multirow{8}{*}{.502} & .985 & 1.016 \\
\hline & & Temperature $\left({ }^{\circ} \mathrm{C}\right)$ & -3.970 & $-9.890^{* * *}$ & & & .408 & 2.451 \\
\hline & & $\operatorname{Wind}(\mathrm{m} / \mathrm{s})$ & -3.428 & -.986 & & & .700 & 1.429 \\
\hline & & Humidity(\%) & .596 & $2.125^{*}$ & & & .437 & 2.290 \\
\hline & & Rainfall(mm) & .014 & .031 & & & .716 & 1.396 \\
\hline & & Fine $\operatorname{dust}\left(\mu \mathrm{g} / \mathrm{m}^{3}\right)$ & -.059 & -.890 & & & .935 & 1.069 \\
\hline & & Sea level(hPa) & .654 & .991 & & & .384 & 2.606 \\
\hline & & Sunshine(hr) & -.184 & -.195 & & & .553 & 1.809 \\
\hline & \multirow{8}{*}{ Top } & Weekend effect & 14.191 & $11.943^{* * *}$ & \multirow{8}{*}{$23.277^{* * *}$} & \multirow{8}{*}{.209} & .985 & 1.016 \\
\hline & & Temperature $\left({ }^{\circ} \mathrm{C}\right)$ & .045 & .522 & & & .409 & 2.446 \\
\hline & & $\operatorname{Wind}(\mathrm{m} / \mathrm{s})$ & 1.217 & 1.656 & & & .701 & 1.427 \\
\hline & & Humidity(\%) & .119 & $2.004^{*}$ & & & .437 & 2.288 \\
\hline & & Rainfall(mm) & -.142 & -1.521 & & & .707 & 1.414 \\
\hline & & Fine $\operatorname{dust}\left(\mu \mathrm{g} / \mathrm{m}^{3}\right)$ & -.006 & -.357 & & & .915 & 1.093 \\
\hline & & Sea level(hPa) & .553 & $3.971^{* * *}$ & & & .387 & 2.581 \\
\hline & & Sunshine(hr) & -.259 & -1.288 & & & .545 & 1.833 \\
\hline & \multirow{8}{*}{ Pants } & Weekend effect & 36.409 & $18.926^{* * *}$ & \multirow{8}{*}{$57.926^{* * *}$} & \multirow{8}{*}{.390} & .983 & 1.017 \\
\hline & & Temperature $\left({ }^{\circ} \mathrm{C}\right)$ & -.666 & $-4.805^{* * *}$ & & & .408 & 2.450 \\
\hline & & $\operatorname{Wind}(\mathrm{m} / \mathrm{s})$ & -.129 & -.108 & & & .698 & 1.432 \\
\hline & & Humidity(\%) & .187 & 1.955 & & & .443 & 2.259 \\
\hline & & Rainfall(mm) & -.181 & -1.182 & & & .711 & 1.406 \\
\hline & & Fine $\operatorname{dust}\left(\mu \mathrm{g} / \mathrm{m}^{3}\right)$ & .015 & .557 & & & .916 & 1.092 \\
\hline & & Sea level(hPa) & .503 & $2.225^{*}$ & & & .385 & 2.597 \\
\hline & & Sunshine(hr) & -.104 & -.323 & & & .557 & 1.795 \\
\hline
\end{tabular}

${ }^{*} p<.05,{ }^{* *} p<.01,{ }^{* * *} p<.001$.

들어 온도 하락폭에 따른 판매량의 규모를 파악하여 평년 기온시의 기본 판매량을 추정하고, 장기 예보에 기반하여 익년의 온도 하강폭을 고려해 수요예측을 시행한다면 온도를 적용한 수요예측 방법이 될 수 있 을 것이다. 또, 시즌이 시작되면 평균기온의 하강에 따라 매장 출고 제품의 종류 및 시기를 조절하여 판
매에 기여할 수 있다.

\section{2) Casual wear}

캐주얼 브랜드에 대해 기상요인이 제품 판매량에 미치는 영향에 대한 분석 결과는〈Table 5〉와 같다. Outer의 경우, 주말효과의 영향이 가장 컸으며, 평균 
$<$ Table 5> Effects of meteorological factors on sales volume of casual wear

\begin{tabular}{|c|c|c|c|c|c|c|c|c|}
\hline \multirow{2}{*}{\multicolumn{2}{|c|}{ Dependent variable }} & \multirow{3}{*}{$\begin{array}{c}\text { Independent variable } \\
\text { Weekend effect }\end{array}$} & \multirow{3}{*}{$\begin{array}{c}\begin{array}{c}\text { Parameter } \\
\text { estimate }\end{array} \\
152.518\end{array}$} & \multirow{2}{*}{$t$} & \multirow{2}{*}{$F$} & \multirow{2}{*}{$R^{2}$} & \multicolumn{2}{|c|}{ Multicollinearity } \\
\hline & & & & & & & Tolerance & VIF \\
\hline \multirow{24}{*}{$\begin{array}{c}\text { Sales } \\
\text { volume of } \\
\text { casual } \\
\text { wear }\end{array}$} & \multirow{8}{*}{ Outer } & & & $20.899^{* * *}$ & \multirow{8}{*}{$73.621^{* * *}$} & \multirow{8}{*}{.448} & .986 & 1.014 \\
\hline & & Temperature $\left({ }^{\circ} \mathrm{C}\right)$ & -4.423 & $-8.382^{* * *}$ & & & .393 & 2.543 \\
\hline & & $\operatorname{Wind}(\mathrm{m} / \mathrm{s})$ & -7.126 & -1.573 & & & .698 & 1.432 \\
\hline & & Humidity(\%) & .802 & $2.200^{*}$ & & & .436 & 2.296 \\
\hline & & Rainfall(mm) & .023 & .042 & & & .700 & 1.429 \\
\hline & & Fine $\operatorname{dust}\left(\mu \mathrm{g} / \mathrm{m}^{3}\right)$ & -.138 & -1.345 & & & .913 & 1.095 \\
\hline & & Sea level(hPa) & .060 & .070 & & & .374 & 2.673 \\
\hline & & Sunshine(hr) & .477 & .387 & & & .549 & 1.822 \\
\hline & \multirow{8}{*}{ Top } & Weekend effect & 115.111 & $21.936^{* * *}$ & \multirow{8}{*}{$79.020^{* * *}$} & \multirow{8}{*}{.469} & .986 & 1.014 \\
\hline & & Temperature $\left({ }^{\circ} \mathrm{C}\right)$ & 2.106 & $5.573^{* * *}$ & & & .402 & 2.486 \\
\hline & & $\operatorname{Wind}(\mathrm{m} / \mathrm{s})$ & -1.607 & -.495 & & & .699 & 1.430 \\
\hline & & Humidity(\%) & .798 & $3.044^{* *}$ & & & .440 & 2.273 \\
\hline & & Rainfall(mm) & -.766 & -1.842 & & & .708 & 1.412 \\
\hline & & Fine $\operatorname{dust}\left(\mu \mathrm{g} / \mathrm{m}^{3}\right)$ & -.217 & $-2.942^{* *}$ & & & .915 & 1.093 \\
\hline & & Sea level(hPa) & .685 & 1.115 & & & .385 & 2.601 \\
\hline & & Sunshine(hr) & 1.971 & $2.219^{*}$ & & & .545 & 1.836 \\
\hline & \multirow{8}{*}{ Pants } & Weekend effect & 71.522 & $25.349^{* * *}$ & \multirow{8}{*}{$84.692^{* * *}$} & \multirow{8}{*}{.487} & .986 & 1.014 \\
\hline & & Temperature $\left({ }^{\circ} \mathrm{C}\right)$ & -.223 & -1.096 & & & .404 & 2.477 \\
\hline & & $\operatorname{Wind}(\mathrm{m} / \mathrm{s})$ & -3.773 & $-2.157^{*}$ & & & .699 & 1.430 \\
\hline & & Humidity(\%) & .142 & 1.001 & & & .440 & 2.273 \\
\hline & & Rainfall(mm) & -.188 & -.837 & & & .708 & 1.413 \\
\hline & & Fine $\operatorname{dust}\left(\mu \mathrm{g} / \mathrm{m}^{3}\right)$ & -.087 & $-2.200^{*}$ & & & .915 & 1.093 \\
\hline & & Sea level(hPa) & -.411 & -1.240 & & & .386 & 2.592 \\
\hline & & Sunshine(hr) & .850 & 1.774 & & & .544 & 1.839 \\
\hline
\end{tabular}

기온이 낮을수록, 습도가 높을수록 판매량이 증가하 는 것으로 나타났고, top의 경우, 주말효과의 영향이 가장 컸고, 온도와 습도, 일조량이 높을수록, 미세먼 지농도가 낮을수록 판매량이 증가하는 것으로 나타 났다. 특히 outer와 pants와는 달리 top은 평균기온이 높을 때 판매량이 증가하는 것으로 분석되어 가을, 겨울동안 기온이 높아지면 소비자들은 쇼핑시 outer
보다는 셔츠나 블라우스 등의 top을 구매하는 경향을 보인다고 예측되었다. pants는 주말효과의 영향이 가 장 컸고, 풍속과 미세먼지농도가 낮을수록 판매량이 증가하는 것으로 나타났다. 풍속의 효과는 Jang and $\operatorname{Lim}(2003)$ 의 연구에서도 밝힌 바 있는 기상요인으로 여름을 제외한 모든 계절에서 영향을 미치며, 가을과 겨울에는 바람이 많이 불수록 매출이 감소한다고 한 
결과를 지지하고 있다. 특히 다른 복종에 비해 캐주 얼 브랜드에 있어서는 모든 품종(outer, top, pants)에 있어서 주말효과와 기상요인이 판매량에 미치는 영 향력이 상대적으로 크게 나타났는데, Jang and Lim (2003)의 연구에서도 여성복에서는 디자이너부틱보 다 캐릭터 캐주얼과 영캐주얼이, 남성복에서는 정장 셔츠보다 캐릭터와 트래디셔널이 기상요인의 영향을 많이 받는다고 보고한 바 있다. 이는 정장류를 사는 고객인 경우, 캐주얼 제품을 사는 고객에 비해 계획 하에 목적구매를 하는 경우가 많을 것이므로 기상요 인의 영향을 덜 받는 것으로 추론된다. 따라서 캐주 얼 브랜드를 판매 시에는 기상요인을 정확하게 예측 하여 보유재고량을 조정할 필요성이 높음을 시사한 다.

\section{3) Sports wear}

스포츠 브랜드에 대해 기상요인이 제품 판매량에 미치는 영향에 대한 분석 결과는 〈Table 6>과 같다. outer의 경우, 주말효과가 판매량에 미치는 영향이 가 장 큰 것으로 나타났고, 평균기온과 미세먼지농도가 낮을수록 판매량에 긍정적인 영향을 미치는 것으로 나타났다. 또한 주말효과는 top과 pants 판매량에 모 두 유의한 영향을 미쳤으며, 미세먼지농도가 낮을수 록 top의 판매량은 증가하였으며, 평균기온이 낮을수 록 pants의 판매량이 증가하는 것으로 나타났다. 강수 량은 전 브랜드에서 유의한 영향을 미치지 않았는데, Jang and Lee(2002), Jang and Lim(2003) 의 연구에 서도 강수량은 겨울보다는 여름에 유의한 영향을 미 치는 기상요인으로 보고되었다.

특히 스포츠 브랜드에서는 다른 복종에 비해서 주 말효과와 기상요인이 판매량에 미치는 영향력이 상 대적으로 낮은 것으로 분석되었다. $\mathrm{A}$ 사의 경우, 스포 츠 브랜드는 다른 신사복이나 캐주얼 브랜드에 비해 몇 배의 매출을 달성하는 브랜드이므로 주말효과와 기상요인이 판매량에 주는 영향도 있긴 하지만, 다른 브랜드에 비해 기본적인 판매 트렌드 및 그 외 변수 에 의해 일별 판매량이 설명되는 정도가 크기 때문이 라고 추론된다. 그러나 기상 요인에 의한 영향력이 존재하며, 매출이 큰 브랜드이므로 일별 판매량으로 산출할 때 큰 숫자로 환산되기 때문에 여전히 기상 요소의 중요성은 고려해야 할 것이다.

\section{Conclusion}

의류기업인 $\mathrm{A}$ 사가 보유하고 있는 브랜드의 $\mathrm{F} / \mathrm{W}$ 시 즌(9월 익년 2월) 일별 판매데이터를 근거로 의류제 품 판매량에 영향을 미치는 요인을 분석하고자 주말 효과와 평균기온, 풍속, 습도, 강수량, 미세먼지농도, 해면기압, 일조량의 기상요인의 영향력을 분석한 결 과는 다음과 같다.

첫째, 주말효과는 모든 브랜드에서 모든 품종에서 제품 판매량에 가장 큰 영향을 주는 요인으로 밝혀졌 다. 전체 판매량에 대한 영향요인을 분석한 결과, 기 상요인 중에서 미세먼지농도가 가장 큰 영향력이 있 는 요소임이 밝혀졌다. 그 다음이 평균기온으로 나타 났는데, 평균기온이 내려갈수록 판매량이 증가하는 것으로 나타나고 있어 $\mathrm{F} / \mathrm{W}$ 시즌 제품을 대상으로 한 결과라고 판단된다.

둘째, 기상요인 중에서 습도, 해면기압, 일조량은 품종별로 부분적으로 판매량에 유의한 영향을 미치 는 것으로 나타났다.

셋째, 복종별로 살펴보면, 신사복 브랜드의 경우는 outer의 경우에 주말효과와 기상요인이 판매량에 미 치는 영향이 pants나 top에 비해 상대적으로 큰 것으 로 분석되었고, 캐주얼 브랜드인 경우는 모든 품종에 있어서 주말효과와 기상요인의 영향력이 큰 것으로 분석되었으며, 스포츠 브랜드에서는 다른 브랜드보다 상대적으로 영향력이 적은 것으로 나타났다.

넷째, 품종별로 살펴보면, 평균기온이 낮을수록 모 든 브랜드의 outer 판매량이 증가하였고, 신사복 브랜 드와 스포츠 브랜드의 pants 판매량이 증가하였으며, top의 판매량에 미치는 영향력은 무의미하였다. 그러 나 캐주얼 브랜드의 top의 경우는 평균기온이 높아질 수록 판매량이 증가하는 것으로 나타났다. 해면기압 은 신사복 브랜드의 top과 pants 판매량에 영향을 미 쳐 해면기압이 높을수록, 즉 날씨가 맑을수록 판매량 이 증가하는 것으로 분석되었다. 습도가 높을수록 신 사복 브랜드와 캐주얼 브랜드의 outer와 top의 판매량 이, 풍속이 높을수록 캐주얼 브랜드의 pants 판매량이 증가하는 것으로 나타났다.

이와 같은 결과를 근거로 한 시사점과 마케팅적 제 안은 다음과 같다.

첫째, 주말 효과는 의류 제품의 판매량에 가장 큰 
$<$ Table 6> Effects of meteorological factors on sales volume of sports wear

\begin{tabular}{|c|c|c|c|c|c|c|c|c|}
\hline \multirow{2}{*}{\multicolumn{2}{|c|}{ Dependent variable }} & \multirow{3}{*}{$\begin{array}{c}\text { Independent variable } \\
\text { Weekend effect }\end{array}$} & \multirow{3}{*}{$\begin{array}{c}\begin{array}{c}\text { Parameter } \\
\text { estimate }\end{array} \\
815.269\end{array}$} & \multirow{2}{*}{$t$} & \multirow{2}{*}{$F$} & \multirow{2}{*}{$R^{2}$} & \multicolumn{2}{|c|}{ Multicollinearity } \\
\hline & & & & & & & \multirow{2}{*}{$\begin{array}{c}\text { Tolerance } \\
.984\end{array}$} & \multirow{2}{*}{$\frac{\mathrm{VIF}}{1.016}$} \\
\hline \multirow{24}{*}{$\begin{array}{c}\text { Sales } \\
\text { volume } \\
\text { of sports } \\
\text { wear }\end{array}$} & \multirow{8}{*}{ Outer } & & & $7.573^{* * *}$ & \multirow{8}{*}{$13.517^{* * *}$} & \multirow{8}{*}{.113} & & \\
\hline & & Temperature $\left({ }^{\circ} \mathrm{C}\right)$ & -39.659 & $-5.018^{* * *}$ & & & .391 & 2.555 \\
\hline & & Wind(m/s) & -40.631 & -.615 & & & .687 & 1.456 \\
\hline & & Humidity(\%) & 3.788 & .713 & & & .450 & 2.222 \\
\hline & & Rainfall(mm) & -2.960 & -.339 & & & .715 & 1.398 \\
\hline & & Fine $\operatorname{dust}\left(\mu \mathrm{g} / \mathrm{m}^{3}\right)$ & -3.583 & $-2.778^{* *}$ & & & .933 & 1.072 \\
\hline & & Sea level(hPa) & -8.803 & -.687 & & & .372 & 2.686 \\
\hline & & Sunshine(hr) & .875 & .049 & & & .564 & 1.773 \\
\hline & \multirow{8}{*}{ Top } & Weekend effect & 144.647 & $3.508^{* *}$ & \multirow{8}{*}{$3.471^{* *}$} & \multirow{8}{*}{.029} & .980 & 1.020 \\
\hline & & Temperature $\left({ }^{\circ} \mathrm{C}\right)$ & -.072 & -.024 & & & .430 & 2.328 \\
\hline & & $\operatorname{Wind}(\mathrm{m} / \mathrm{s})$ & 9.806 & .386 & & & .680 & 1.470 \\
\hline & & Humidity(\%) & 3.495 & 1.711 & & & .448 & 2.233 \\
\hline & & Rainfall(mm) & -.116 & -.032 & & & .726 & 1.378 \\
\hline & & Fine $\operatorname{dust}\left(\mu \mathrm{g} / \mathrm{m}^{3}\right)$ & -1.297 & $-2.635^{* *}$ & & & .935 & 1.069 \\
\hline & & Sea level(hPa) & 8.259 & 1.696 & & & .392 & 2.549 \\
\hline & & Sunshine(hr) & 11.767 & 1.682 & & & .561 & 1.781 \\
\hline & \multirow{8}{*}{ Pants } & Weekend effect & 178.969 & $5.203^{* * *}$ & \multirow{8}{*}{$14.220^{* * *}$} & \multirow{8}{*}{.120} & .984 & 1.016 \\
\hline & & Temperature $\left({ }^{\circ} \mathrm{C}\right)$ & -16.893 & $-6.695^{* * *}$ & & & .407 & 2.460 \\
\hline & & $\operatorname{Wind}(\mathrm{m} / \mathrm{s})$ & -30.546 & -1.450 & & & .687 & 1.455 \\
\hline & & Humidity(\%) & .931 & .549 & & & .448 & 2.233 \\
\hline & & Rainfall(mm) & -.342 & -.123 & & & .714 & 1.400 \\
\hline & & Fine $\operatorname{dust}\left(\mu \mathrm{g} / \mathrm{m}^{3}\right)$ & -.787 & -1.922 & & & .935 & 1.070 \\
\hline & & Sea level(hPa) & -2.041 & -.498 & & & .379 & 2.638 \\
\hline & & Sunshine(hr) & 1.359 & .236 & & & .563 & 1.777 \\
\hline
\end{tabular}

${ }^{*} p<.05,{ }^{* *} p<.01,{ }^{* * *} p<.001$.

영향을 주는 요인이므로 의류업체들은 주말 동안의 고객의 방문을 유도하기 위한 판매촉진 전략과 이벤 트를 기획하는 것이 중요하다.

둘째 최근의 미세먼지 농도가 높은 날이 많아짐에 따라 미세먼지 농도가 의류제품 판매량에 영향을 미 치는 가장 주요한 기상요인으로 밝혀졌으므로, 의류
기업들은 기상요인 중 미세먼지농도를 주목해야 함 을 시사한다. 신사복 브랜드보다는 캐주얼과 스포츠 브랜드에 있어서 제품 판매량에 유의한 영향을 주는 것으로 나타났는데, 이는 미세먼지농도에 따라 소비 자들의 야외활동에 제한이 있음을 시사한다. 특히 캐 주얼과 스포츠 브랜드는 미세먼지농도를 관측함으로 
써 고객의 방문률을 예측할 수 있을 것이며, 판매관 리, 재고관리 등에 활용할 수 있을 것이다.

셋째, 기상요인 중 평균기온은 대부분의 선행연구 에서도 밝혀졌듯이, 의류제품 판매량에 영향을 미치 는 주요한 기상요인 중의 하나로 분석되었다. 가을, 겨울 동안의 기온 변화를 정확히 탐색하여 기온의 하 강 시점에 맞춰 재고량을 확보하는 것이 필요하며, 특히 기온의 하강에 따라 outer와 pants의 판매량은 영향을 받는 주요한 아이템으로 밝혀졌으므로 기온 변화에 따른 상품구색 전략도 필요하다고 하겠다.

넷째, 기상요인이 의류제품 판매량에 영향을 미치 는 것으로 밝혀졌으므로, 과거의 기상요인과 판매량 과의 분석을 통한 데이터베이스를 마련한다면 해당 시즌의 정확한 기상요인의 변화에 따른 수요예측이 가능할 것이며, 이에 따른 생산량 조절, 점포의 입고 시기와 물량 결정으로 인해 최적의 재고관리 전략을 수립할 수 있을 것이다. 또한 브랜드의 상품 기획 시 기상 요인을 제외한 판매량을 도출할 수 있을 것이 다.

본 연구는 $\mathrm{A}$ 의류기업의 실제 판매데이터를 기반 으로 의류제품 판매량에 영향을 미치는 주말효과와 기상요인을 실증적으로 입증하였다는데 의의가 있다. 특히 기상요인의 영향이 복종별, 품종별로 상이하게 나타나고 있어, 의류제품의 판매량을 예측하는데 있 어서 복종과 품종에 따라 기상요인의 영향을 반영한 체계적인 판매량 예측모형을 구축할 필요성이 있음 을 시사한다. 그러나 기상요인과 판매량간의 관계에 대한 선행연구가 부족하여 기존 결과와의 논의가 부 족하였고, $\mathrm{A}$ 기업이 보유하고 있는 의류 브랜드의 $\mathrm{F} / \mathrm{W}$ 판매량 데이터만을 이용하였으므로 일반화하는 데는 한계가 있을 수 있겠다. 또한 순수한 기상효과 만을 정확히 분석하기 위해서는 판매량에 영향을 미 칠 수 있으리라 예측되는 다른 변수들, 예를 들어 점 포의 종류와 위치, 세일 기간이나 할인율, 브랜드 명 성 등이 통제되어야 하므로 추후 이러한 변수들을 고 려한 분석이 이루어져야 할 것이다.

\section{References}

Agnew, M. D., \& Palutikof, J. P. (1999). The impacts of climate on retailing in the UK with par- ticular reference to the anomalously hot summer of 1995. International Journal of Climatology, 19(13), 1493-1507. doi:10.1002/(SICI)1097-0088 (19991115)19:13<1493::AID-JOC455>3.0.CO;2-V

Ahn, K. H. (2008). The effect of weather on firm's sales. Unpublished master's thesis, Sejong University, Seoul, Korea.

Arunraj, N. S., \& Ahrens, D. (2016). Estimation of non-catastrophic weather impacts for retail industry. International Journal of Retail \& Distribution Management, 44(7), 731-753. doi:10.1108/ IJRDM-07-2015-0101

Bahn, K. S. (2011). 워렌 버핏이 날씨시장으로 간 까 닭은?: 날씨를 알면 경제가 보인다 [Why Warren Buffett goes to the weather market]. Seoul: Planet media.

Bahng, Y., \& Kincade, D. H. (2012). The relationship between temperature and sales: Sales data analysis of a retailer of branded women's business wear. International Journal of Retail \& Distribution Management, 40(6), 410-426. doi:10. 1108/09590551211230232

Bertrand, J.-L., Brusset, X., \& Fortin, M. (2015). Assessing and hedging the cost of unseasonal weather: Case of the apparel sector. European Journal of Operational Research, 244(1), 261276. doi:10.1016/j.ejor.2015.01.012

Byun, H. R. (2000). 일상생활의 기상학 [Meteorology of everyday life]. Seoul: Sigma Press.

Hong, J.-H., Lee, H.-J., \& Na, J.-H. (2012). Effects of meteorological factors on the sales of seasonal products. Korea Research Academy of Distribution and Management Review, 15(6), 5-15.

Jang, E. Y., \& Lee, S. J. (2002). The effects of meteorological factors on sales of apparel products: Focused on apparel sales in the department store. Journal of the Korean Society of Costume, 52(2), 139-150.

Jang, E. Y., \& Lim, B. H. (2003). An exploratory study on the effect of weather factors on sales of fashion apparel products in department stores. 
Journal of Global Scholars of Marketing Science, 12, 121-134.

Ji, H.-K., \& Kim, H. S. (2010). Clothing wearing and influencing factors according to weather and temperature. Journal of the Korean Society of Clothing and Textiles, 34(11), 1900-1911. doi:10. 5850/JKSCT.2010.34.11.1900

Kim, D. S., \& Kim, J. H. (2006). 날씨경영: 하늘에서 돈이 옵니다 [Weather marketing: Money comes from the sky]. Seoul: Maeil Business Newspaper Publishing.

Korea Meteorological Administration. (2014, June 23). 블랙야크, "대한민국 기상산업대상" 대상 수 상 [Press Release for Weather Industry Awards, Black Yak won the best weather industry in the year]. Retrieved February 10, 2017, from http:// web.kma.go.kr/notify/press/kma_list.jsp?bid= press \&mode $=$ view\&num $=1192840$

Lee, H. S. (1997), 하늘도 내 편으로 만드는 기상 마 케팅 [Weather marketing which makes the sky on my side]. LG Business Insight, 439, 52-59.

Lee, Y.-K., Ahn, K.-H., \& Chung, N. H. (2011). An effect of weather on firm's sales on clothes shop. Journal of the Korean Data Analysis Society, 13(1), 491-503.

Marteau, D., Carle, J., Fourneaux, S., Holz, R., \& Moreno, M. (2004). La gestion du risque climatique [Climate risk management]. Paris: Econo- mica.

Niemira, M. P. (2005). Weather matters. Research Review, 12(2), 23-27.

Park, H. Y. (2013, June 24). 이른 장마에 레인부츠 대박 [Rainboots hit the early rainy season] Apparel News, Retrieved February 10, 2017, from http://www.appnews.co.kr/2011/pnews.php?table $=$ paper_news\&query $=$ view\&uid $=68683$

Park, S. A. (2004). The influence of weather conditions on sales in discount stores. Unpublished master's thesis, Konkuk University, Seoul, Korea.

Parsons, A. G. (2001). The association between daily weather and daily shopping patterns. Australasian Marketing Journal (AMJ), 9(2), 78-84. doi: 10.1016/S1441-3582(01)70177-2

Rowley, J. (1999). Loyalty, the internet and the weather: The changing nature of marketing information systems?. Management Decision, 37(6), 514-519. doi:10.1108/00251749910278032

Stoltman, J. J., Morgan, F. W., \& Anglin, L. K. (1999). An investigation of retail shopping situations. International Journal of Retail \& Distribution Management, 27(4), 145-153. doi:10.1108/09590559910268453

Yun, J. W. (1999). System models for building the strategic information system of department store. Unpublished master's thesis, Soongsil University, Seoul, Korea. 